\title{
Psychological Empowerment on Job Performance-Mediating Effect of Job Satisfaction
}

\author{
Xiujun Sun \\ Jinan University, Guangzhou, China \\ Email: 446051475@qq.com
}

Received 21 March 2016; accepted 23 April 2016; published 26 April 2016

Copyright (C) 2016 by author and Scientific Research Publishing Inc.

This work is licensed under the Creative Commons Attribution International License (CC BY). http://creativecommons.org/licenses/by/4.0/

c) (i) Open Access

\begin{abstract}
This research mainly explores the relationship between psychological empowerment and job performance and their internal mechanisms from psychological empowerment of employees, and discusses job satisfaction and organizational justice multiple mediation effect between psychological empowerment and job performance. The study mainly adopts the methods of questionnaires, including web questionnaires survey and field questionnaires survey. Conclusions are as follows: Conclusion 1: Psychological empowerment, work meaning, competence, impact and self-determination and job performance significantly relate each other. Conclusion 2: Psychological empowerment, job performance, job satisfaction and organizational justice significantly relate each other. Conclusion 3: Regression analysis demonstrates that job satisfaction acts as the mediator between psychological empowerment and job performance.
\end{abstract}

\section{Keywords}

Psychological Empowerment, Job Satisfaction, Job Performance, Mediating Effect

\section{Introduction}

For decades, enterprise managers and researchers have done many researches on empowerment. At the beginning, researchers lay much more importance to how to enforce the empowerment measures, but receive very little effects. As time goes by, by the end of 1990s, psychological empowerment era came, thus researchers paid much more attention to the psychological empowerment. Thomas et al. firstly put forward the concept of psychological empowerment which means the positive experience which employees gain from motivated and satisfied work. In their theory, psychological empowerment includes four cognitive dimensions: meaning, autonomy, 
self-efficacy and impact.

\section{Theoretical Summary and Hypotheses}

\subsection{Psychological Empowerment and Job Performance}

As the term psychological empowerment was created, researchers have been paying close attention to the relationship with job performance. Because the ultimate purpose to study psychological empowerment is to improve job performance. Currently, the results about how psychological empowerment affects job performance were not consistent. For example, Liden et al. (Liden, Wayne, \& Sparrowe, 2000) used four-dimensional structure of psychological empowerment scale developed by Spreitzer to study how the four dimensions affect job performance, and found that self-efficacy have a significant positive impact on job performance. However, Dewettinck (Dewettinck, Buyens, \& Singh, 2004) found that psychological empowerment can increase employees' job satisfaction, but the impact on job performance is not obvious. So we propose Hypothesis 1: Psychological empowerment of employees significantly related to and predict job performance.

\subsection{Psychological Empowerment and Job Satisfaction}

The study of psychological empowerment expands the range of job satisfaction to some extent. Studies have shown that the perception of psychological empowerment associated with job satisfaction. In 1997, Spreitzer presents that meaning, autonomy and self-efficacy of psychological empowerment have positive relationship with job satisfaction. The study of Chinese scholar Li et al. (Li, Li, \& Shi, 2006) shows that four dimensions of psychological empowerment related to job satisfaction, turnover intention, organizational commitment and job burnout. in which self-efficacy has a positive impact on employee satisfaction. Zeng (2009) found that psychological empowerment has a significant positive correlation with job satisfaction. Based on those results, we propose Hypothesis 2: Psychological empowerment of employees significantly related to and predict job satisfaction.

On the basis of Hypothesis 1 and Hypothesis 2, we propose the third hypothesis: psychological empowerment affects job performance through job satisfaction.

\section{Research Methods}

\subsection{Participants}

The participants of survey questionnaire are the employees of various types of enterprises in whole country, sending out questionnaire 600 , valid recycles 573 , effectiveness is $95.5 \%$ (Table 1 ).

\subsection{Research Materials}

The independent variable of this paper is psychological empowerment and the dependent variable is job perfor-

Table 1. Sample distribution of psychological empowerment questionnaire $(N=573)$.

\begin{tabular}{|c|c|c|c|}
\hline Type & Sample Distribution & Number & Percentage \\
\hline \multirow{2}{*}{ Gender } & Male & 306 & $53.4 \%$ \\
\hline & Female & 267 & $46.6 \%$ \\
\hline \multirow{4}{*}{ Age } & Under 20 (including 20) & 100 & $17.5 \%$ \\
\hline & 20 to 25 (including 25) & 358 & $62.5 \%$ \\
\hline & 25 to 30 (including 30) & 95 & $16.6 \%$ \\
\hline & Above 30 & 19 & $3.4 \%$ \\
\hline \multirow{2}{*}{ Marriage status } & Unmarried & 507 & $88.5 \%$ \\
\hline & Married & 66 & $11.5 \%$ \\
\hline \multirow{4}{*}{ Education background } & High school or below & 64 & $11.1 \%$ \\
\hline & Junior college & 176 & $30.7 \%$ \\
\hline & Bachelor & 267 & $46.6 \%$ \\
\hline & Master or above & 66 & $11.5 \%$ \\
\hline
\end{tabular}


mance. After summarizing research results and referring to the relevant literature. We design the questionnaire Which is made up of four parts:

1) Psychological empowerment scale: This scale which has 12 items of four dimensions is developed by Spreitzer (1995) and revised by Li et al. (Li, Li, \& Shi, 2006) in China. Li tested the adaptability of the scale under Chinese cultural background. They investigate 20 companies sending 942 questionnaires and conduct confirmatory factor analysis and internal consistency analysis. It turns out that the scale has good validity and reliability.

The four-dimensional model of Spreitzer psychological empowerment has been well verified in China, four dimensions are as follows.

Meaning (three items) refers to the cognition of job objectives and values based on their value system and standards.

Autonomy (three items) refers to the individual's ability to control work activities.

Self-efficacy (three items) means the assessment on their own individual ability to work.

Impact (three items) refers to the extent the individual think they can influence results of the organization on strategy, administration, management and operations.

The questionnaire is a five-point type scale. 1 means strongly disagree while 5 refers to strongly agree. The greater the value, the higher the level of psychological empowerment.

2) Job satisfaction scale this study used is called job satisfaction index scale which developed by Brayfiled and Rothe. The scale predominantly measures general satisfaction of employees and consists of six items, forming a comprehensive description of job satisfaction. In the scale, the work itself, leaders, colleagues, income, promotion opportunities and overall job satisfaction are assessed.

The questionnaire is also a five-point type scale. 1 means strongly disagree while 5 refers to strongly agree. The greater the value, the higher the level of job satisfaction.

3) Job performance scale consists of task performance and contextual performance. Task performance scale mainly references Xie Jinshan (2001) thesis to design, which included three aspects of work performance, quality and goal achievement. Contextual performance mainly references Yao Lixia (2002) thesis to design.

The questionnaire is also a five-point type scale. 1 means strongly disagree while 5 refers to strongly agree. The greater the value, the higher the level of job performance.

\section{Results}

\subsection{Reliability Test}

We retest reliability of each scale using coefficient of internal consistency (Crobacha coefficient) in SPSS 22.0. The coefficient of each scale is as follows: psychological empowerment scale 0.86 , job performance scale 0.88 , job satisfaction 0.83 , all the coefficients are above 0.80 . It turns out that all the scales have a good reliability.

\subsection{Descriptive Statistics Results}

\subsubsection{The Correlation Analysis between Psychological Empowerment and Job Performance}

The correlation analysis of each dimension of psychological empowerment and job performance are shown as follows. Meaning, autonomy, self-efficacy and impact of psychological empowerment are significantly and positively correlated with task performance and contextual performance of job performance at 0.01 level. That means the higher level of individual psychological empowerment, the higher of their job performance; vice versa, the lower level of individual psychological empowerment, the lower of their job performance (Table 2).

Table 2. Correlation analysis of psychological empowerment and job performance.

\begin{tabular}{|c|c|c|c|c|c|}
\hline & & Meaning & Autonomy & Self-efficacy & Impact \\
\hline \multirow{3}{*}{ Task Performance } & Pearson correlation & $0.350^{* *}$ & $0.380^{* *}$ & $0.518^{* *}$ & $0.395^{* *}$ \\
\hline & Significance & 0.000 & 0.000 & 0.000 & 0.000 \\
\hline & $\mathrm{N}$ & 296 & 296 & 296 & 296 \\
\hline \multirow{3}{*}{ Contextual Performance } & Pearson correlation & $0.511^{* *}$ & $0.408^{* *}$ & $0.432^{* *}$ & $0.380^{* *}$ \\
\hline & Significance & 0.000 & 0.000 & 0.000 & 0.000 \\
\hline & $\mathrm{N}$ & 296 & 296 & 296 & 296 \\
\hline
\end{tabular}

Notes: ${ }^{* *}$ means significantly correlated at 0.01 level. 


\subsubsection{The Correlation Analysis between Psychological Empowerment and Job Satisfaction}

The correlation analysis of each dimension of psychological empowerment and job satisfaction are shown as follows. Meaning, autonomy, self-efficacy and impact of psychological empowerment are significantly and positively correlated with job satisfaction at 0.01 level. That means the higher the level of individual psychological empowerment, the higher level of their job satisfaction; vice versa, the lower the level of individual psychological empowerment, the lower level of their job satisfaction (Table 3).

\subsubsection{The Correlation Analysis between Job Satisfaction and Job Performance}

The correlation analysis of two dimensions of job performance and job satisfaction are shown as follows. Task performance and contextual performance of job performance are significantly and positively correlated with job satisfaction at 0.01 level. That means the higher the level of individual job satisfaction, the higher the level of their job performance; vice versa, the lower the level of individual psychological empowerment, the lower the level of their job performance (Table 4).

\subsection{Mediating Effect Analysis of Psychological Empowerment, Job Satisfaction and Job Performance}

In this study, we use Baron and Kenny's (1986) three-step method to explore the mediator effect. The specific three steps are as follows: Step 1: Regress the dependent variable on the independent variable. In other words, confirm that the independent variable is a significant predictor of the dependent variable. Step 2: Regress the mediator on the independent variable. In other words, confirm that the independent variable is a significant predictor of the mediator. If the mediator is not associated with the independent variable, then it couldn't possibly mediate anything. Step 3: Regress the dependent variable on both the mediator and independent variable. In other words, confirm that the mediator is a significant predictor of the dependent variable, while controlling for the independent variable. This step involves demonstrating that when the mediator and the independent variable are used simultaneously to predict the dependent variable, the previously significant path between the independent and dependent variable is now greatly reduced, if not significant.

We use "enter" method to which means several independent variables simultaneously put in the equation. There are some indexes to judge the regression effect. The F value, the bigger the better. The so-called coefficient of determination $\mathrm{R}^{2}$, the closer to 1 the better.

\subsubsection{Regression Analysis of Psychological Empowerment on Job Performance}

To explore the prediction effect of psychological empowerment on job performance, we adopt "enter" regression analysis method, taking psychological empowerment and its four dimensions as the independent variable, job performance and its two dimensions as the dependent variable. Here's the result.

F-test value in regression analysis of psychological empowerment on task performance and contextual performance of job performance is significant at 0.01 level, where regression coefficients of meaning and self-efficacy on

Table 3. Correlation analysis of psychological empowerment and job satisfaction.

\begin{tabular}{cccccc}
\hline & & Meaning & Autonomy & Self-efficacy & Impact \\
\hline & Pearson correlation & $0.455^{* *}$ & $0.283^{* *}$ & $0.313^{* *}$ & $0.388^{* *}$ \\
Job Satisfaction & Significance & 0.000 & 0.000 & 0.000 & 0.000 \\
& $\mathrm{~N}$ & 296 & 296 & 296 & 296 \\
\hline
\end{tabular}

Notes: ${ }^{* *}$ means significantly correlated at 0.01 level.

Table 4. Correlation analysis between job satisfaction and job performance.

\begin{tabular}{cccc}
\hline & & Task Performance & Contextual Performance \\
\hline \multirow{3}{*}{ Job Satisfaction } & Pearson correlation & $0.571^{* *}$ & $0.563^{* *}$ \\
& Significance & 0.000 & 0.000 \\
& $\mathrm{~N}$ & 296 & 296 \\
\hline
\end{tabular}

Notes: ${ }^{* *}$ means significantly correlated at 0.01 level. 
task performance and contextual performance of job performance are significant (Table 5).

Now that psychological empowerment significantly predict job performance, to better explore its internal mechanism and know how psychological empowerment affects job performance, we would analyze how job satisfaction works between psychological empowerment and job performance.

\subsubsection{Mediating Effect Analysis of Job Satisfaction on Psychological Empowerment and Job Performance}

To better explore how job satisfaction works between psychological empowerment and job performance, we do regression analysis among job satisfaction, psychological empowerment and job performance. The results are as follows (Table 6).

Regression analysis shows that the mediating effect of job satisfaction is significant. In the first step of regression analysis, the Beta value is 0.624 when taking psychological empowerment as predictor variable and job performance as dependent variable. Moreover, the regression coefficient is significant. In the second step of regression analysis, the Beta value is 0.494 when taking psychological empowerment as predictor variable and job satisfaction as dependent variable. Moreover, the regression coefficient is significant, too. In the third step of regression analysis, taking psychological empowerment and job satisfaction as predictor variables, job performance as dependent variable, the Beta value of psychological empowerment is 0.417 , declining 0.207 compared with the first step. So we conclude that job satisfaction partly mediates the relationship between psychological empowerment and job performance. Specifically, The mediating effect is 0.207 , made up $33.17 \%$ of the total effect.

\section{Analysis and Discussion}

\subsection{Correlation Analysis}

Correlation analysis showed that, employees' psychological empowerment has a significant positive correlation with job performance, that means, employees who have higher degree of psychological empowerment also have

Table 5. Regression analysis of psychological empowerment on job performance.

\begin{tabular}{|c|c|c|c|c|}
\hline & Standardized Coefficients $\beta$ & $\mathrm{F}$ & df & Adjusted $\mathrm{R}^{2}$ \\
\hline Dependent Variable: Task Performance & & $40.034^{* *}$ & 295 & 0.346 \\
\hline Meaning & $0.211^{* *}$ & & & \\
\hline Autonomy & 0.017 & & & \\
\hline Self-efficacy & $0.410^{* *}$ & & & \\
\hline Impact & 0.158 & & & \\
\hline Dependent Variable: Contextual Performance & & $46.415^{* *}$ & 295 & 0.381 \\
\hline Meaning & $0.413^{* *}$ & & & \\
\hline Autonomy & -0.004 & & & \\
\hline Self-efficacy & $0.307^{* *}$ & & & \\
\hline Impact & $0.125^{*}$ & & & \\
\hline
\end{tabular}

Notes: ${ }^{* *}$ means significantly correlated at 0.01 level;

* means significantly correlated at 0.05 level;

Independent variable: psychological empowerment; dependent variable: job performance.

Table 6. Regression analysis among job satisfaction, psychological empowerment and job performance.

\begin{tabular}{|c|c|c|c|}
\hline \multirow[b]{2}{*}{ Step 1} & \multirow{2}{*}{$\begin{array}{l}\text { Standardized Regression Equation } \\
\qquad \mathrm{Y}=0.624 \mathrm{X}\end{array}$} & \multicolumn{2}{|c|}{ Regression Coefficient Test } \\
\hline & & $\mathrm{SE}=0.043$ & $\mathrm{t}=13.694^{* *}$ \\
\hline Step 2 & $M=0.494 X$ & $\mathrm{SE}=0.06$ & $t=9.738^{* *}$ \\
\hline Step 3 & $Y=0.417 X$ & $\mathrm{SE}=0.043$ & $\mathrm{t}=8.98^{* *}$ \\
\hline & $0.419 \mathrm{M}$ & $\mathrm{SE}=0.037$ & $\mathrm{t}=9.02^{* *}$ \\
\hline
\end{tabular}

Notes: ${ }^{* *}$ means significantly correlated at 0.01 level; Y: job performance; M: job satisfaction; X: psychological empowerment. 
higher level of job performance. Specifically, the psychological empowerment has four dimensions which are meaning, autonomy, self-efficacy and impact. Task performance has two dimensions, contextual performance and task performance. They all have positive correlation with each other. Further regression analysis showed that all of the four dimensions of psychological empowerment including meaning, autonomy, self-efficacy and impact can significantly predict job performance that means employees who have higher degree of psychological empowerment also have higher level of job performance.

Employees' psychological empowerment is an indicator of the extent of work involvement, affecting many aspects of staff's work. If an employee has higher degree of psychological empowerment, he or she is more likely to receive the hint from his boss or organization about work. So it is easier for him or her to perceive the meaning of work and increase job autonomy, therefore he or she think more about whether his or her job can affect the strategy and management of company. So employees with higher degree of psychological empowerment will be more motivated to work harder and their performance will be correspondingly higher.

These findings have a good inspiration on the incentive mechanism of the organization. Organizational incentives always relate with remuneration, leadership style and organizational climate. Moreover organizational incentives can also improve employees' job performance through improving employees' psychological empowerment.

In this study, correlation analysis showed that psychological empowerment and job satisfaction are both have significant correlation with job performance. Specifically, psychological empowerment has significant correlation with job performance. That menas if an employee has a higher score on psychological empowerment, he will be more satisfied with his work, indicating that the higher level of psychological empowerment, the higher job satisfaction. Employees with higher level of psychological empowerment will perceive higher level of work meaning. That means the employees are more likely to think their own values, beliefs and behaviors are matching their work, more likely to think this is their perfect work and their performance will be correspondingly higher.

Job satisfaction has a significant positive correlation with job performance, if employees with higher score on job satisfaction, they also has higher job performance. That means the more satisfied with work they are, the higher job performance they have. So if employees are more satisfied with their work, he will be more positive to work and improve work autonomy significantly, and if employees are more satisfied with their work, he can find the meaning of work more easily. Overall speaking, employees with higher psychological empowerment will have higher job satisfaction.

In summary, this paper proposed a new idea to study enterprise incentive system through improving job satisfaction to improve work performance.

\subsection{Mediating Effect of Job Satisfaction}

Further regression analysis showed that psychological empowerment is a significant predictor on job performance; job satisfaction is a significant predictor on job performance. When considering the psychological empowerment and job satisfaction as the predictor variables at the same time and job performance as the dependent variable, job satisfaction reduced regression coefficients from psychological empowerment to job performance. Thus we can conclude that job satisfaction is an intermediary variable between psychological empowerment and job performance, which is consistent with the hypothesis. The results imply that the organizations can improve employees' job performance by improving their satisfaction.

\section{Conclusions and Expectations}

\subsection{Conclusions}

This paper preliminarily studied psychological empowerment of employees, their job performance and its internal mechanism by questionnaire, examining the relationship between psychological empowerment and job performance of employees and the intermediary role that job satisfaction plays between psychological empowerment and job performance. The results are as follows:

Conclusion 1: Psychological empowerment, work meaning, competence, impact and self-determination and job performance significantly relate each other.

Conclusion 2: Psychological empowerment, job performance, job satisfaction and organizational justice sig- 
nificantly relate each other.

Conclusion 3: Regression analysis demonstrates that job satisfaction acts as the mediator between psychological empowerment and job performance.

Previous studies on psychological empowerment and job performance predominantly focus on the relationship between each other, but this paper discusses how psychological empowerment affects job performance based on the previous studies and concludes that job satisfaction plays a partial mediating role between psychological empowerment and job performance by empirical studies.

\subsection{Expectations}

Although I do my best to carefully design the study, there are still some deficiencies due to constraints. 1) This research studied by questionnaire, but this method has certain limitations. Data may be not so accurate due to halfhearted participants. Future research can consider using experimental methods to derive a more explicit result. 2) Limited by personal ability, the number of subjects who has worked more than ten years is small, even less than ten people.

This paper discusses the influence of psychological empowerment on job performance, and psychological empowerment how to affect job performance through job satisfaction. The theoretical model constructed in this study only relates to the mediator variable, and it is possible to be moderator variable in the influence path of psychological empowerment, job satisfaction and job performance. Future research needs to explore other affecting mechanisms of psychological empowerment on job performance.

\section{References}

Dewettinck, K., Buyens, D., \& Singh, J. (2004). Psychological Empowerment in the Workplace: Reviewing the Empowerment Effects on Critical Work Outcomes. Vlerick Leuven Gent Management School Working Paper.

Li, C. P., Li, X. X., \& Shi, K. (2006). The Measurement of Empowerment and Its Relationship with Work Attitude of Employees. Journal of Psychology, 38, 99-106.

Liden, R. C., Wayne, S. J., \& Sparrowe, R. T. (2000). An Examination of the Mediating Role of Psychological Emprovement on the Relations between the Job, Interpersonal Relationships, and Work Outcomes. Journal of Applied Psychology, 85, 407-416. http://dx.doi.org/10.1037/0021-9010.85.3.407

Spreitzer, G. M. (1995). Psychological Empowerment in the Workplace: Dimensions, Measurement, and Validation. Academy of Management Journal, 38, 1442-1465. http://dx.doi.org/10.2307/256865

Zeng, L. Z. (2009). An Empirical Study of Relationship between Psychological Empowerment and Job Satisfaction on Hotel Staff. Xiangtan: Xiangtan University. 